\title{
Primary extranodal marginal zone B-cell lymphoma with diffuse uveal involvement and focal infiltration of the trabecular meshwork: a case report and review of literature
}

\author{
Xinxiao Gao ${ }^{1,2}$, Bin Li ${ }^{1}$, Qisheng You ${ }^{1}$ and Xiaoyan Peng ${ }^{1 *}$
}

\begin{abstract}
Background: Primary extranodal marginal zone lymphoma (EMZL) of the uvea is a rare condition and diagnosis may be challenging. We aim to report the clinical, histopathologic and immunohistochemical findings in a case of primary EMZL with diffuse uveal involvement and focal infiltration of the trabecular meshwork.

Case presentation: A 38-year-old male presented with 2-year progressive vision loss in the right eye. Fundus examination showed choroidal thickening with diffuse retinal pigment epithelium (RPE) changes and inferior exudative retinal detachment. Ultrasonography revealed low-reflective masses with diffuse thickening of the choroid involving the optic nerve and orbit. Despite treatment with steroids, his symptoms progressed over time. One year later, visual acuity of the right eye markedly decreased to no light perception and enucleation was performed. Histopathological findings revealed infiltrates of malignant cells in the choroid, iris, ciliary body and trabecular meshwork. Immunohistochemistry confirmed the diagnosis of primary uveal EMZL.
\end{abstract}

Conclusions: This is the first case reporting primary EMZL diffusely involving the uvea with focal infiltration of the trabecular meshwork.

\section{Background}

Ophthalmic lymphomas account for approximately $10 \%$ of all extranodal malignant lymphomas [1,2]. The major subtype of ophthalmic lymphoma is extranodal marginal zone lymphoma (EMZL) of mucosa-associated lymphoid tissue (MALT) [3,4]. It presents an indolent clinical course and usually involves the conjunctiva, lacrimal gland, and orbit. Intraocular choroidal involvement is a rare condition. Primary iris and ciliary body EMZL are exceptionally rare with only a handful of cases reported in the literature [5-7].

In this study, we present a rare case of EMZL diffusely involving the uvea with focal involvement of trabecular meshwork and review of reported cases. The study was approved by institutional review committee of Beijing

\footnotetext{
* Correspondence: drpengxy@yeah.net

'Beijing Institute of Ophthalmology, Beijing Ophthalmology and Visual Science Key Lab, Beijing Tongren Eye Center, Beijing Tongren Hospital, Capital Medical University, 17 Hougou Lane, Chongnei Street, Beijing 100005, China

Full list of author information is available at the end of the article
}

Tongren Hospital, Capital Medical University and was conducted in accordance with the tenets of the Declaration of Helsinki. Written informed consent was obtained from the patient.

\section{Case presentation}

In November 2012, a 38-year-old male presented with 2 -year progressive vision loss in his right eye. He was referred to our clinic for a choroidal lesion with subretinal fluid in the right eye. He had been generally healthy and denied any significant past medical history including diabetes mellitus and hypertension. Since 2010, the onset of the vision decrease, a flat serous retinal detachment in his right eye was detected by a local ophthalmologist. However, no treatment was given, for the diagnosis was unclear at that moment. After several outpatient follow-ups, the disease progressed gradually. One year later, he visited another ophthalmologist for a second opinion. At that time, a choroidal mass with associated serous retinal detachment was detected, yet no treatment was performed, for 

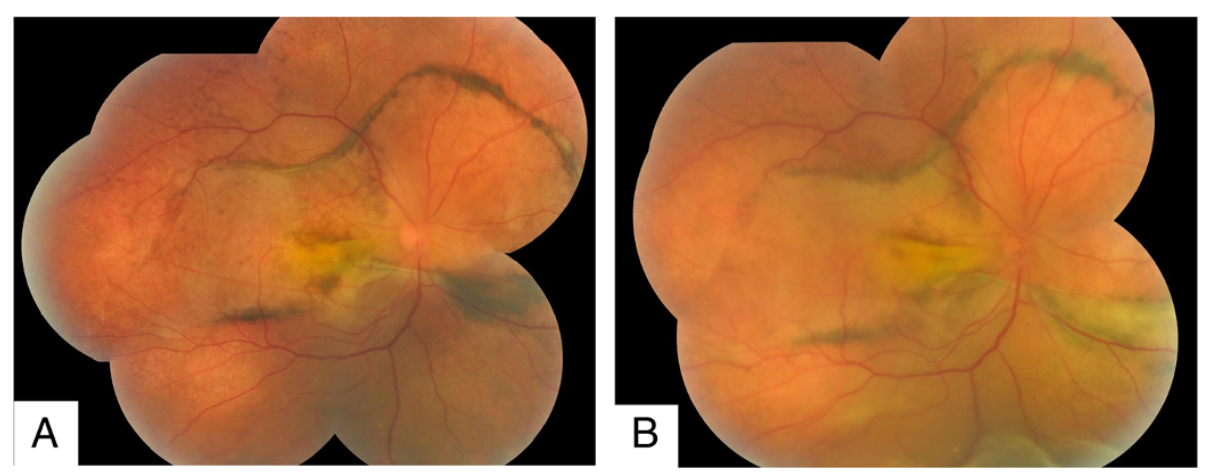

Figure 1 Fundus colour photograph. (A) Choroidal thickening was shown, with diffuse retinal pigment epithelium (RPE) changes and inferior exudative retinal detachment. (B) Deteriorated retinal detachment was demonstrated.

the diagnosis remained unclear. At his initial visit to our institute, best corrected visual acuity was 20/200 in the right eye and 20/16 in the left eye. Intraocular pressure of both eyes was within normal limits. Examination of the left eye was unremarkable. Right eye anterior segment was normal. Fundus examination revealed choroidal thickening with diffuse retinal pigment epithelium (RPE) changes and inferior exudative retinal detachment (Figure 1A). Fluorescein angiography showed nonspecific leakage at the level of the RPE and formation of macular edema, combined with thickening of the choroid and serous retinal detachment (Figure 2A-B). Ultrasonography showed lowreflective masses with diffuse thickening of the choroid and involvement of optic nerve and orbit (Figure 3A-B). A suspicious diagnosis of posterior scleritis or choroidal hemangioma was made. Retrobulbar twenty-milligram triamcinolone acetonide was then given. However, the ocular findings were unchanged. One week later, he received experimental treatment of intravitreal ranibizumab.

The patient was loss to follow up until 6 months after intravitreal ranibizumab injection. Magnetic resonance imaging (MRI) of the orbits confirmed extensive choroidal thickening involving the optic disc with a height of $0.37 \mathrm{~cm}$. Two lobulated soft tissue masses were seen around the optic nerve. Fundoscopy revealed deteriorated retinal detachment (Figure 1B). The patient and his family refused to undergo aggressive treatment, including biopsy. One year later, patient returned to our clinic with visual acuity of no light perception on the right eye. Since the etiology of the mass was uncertain, enucleation was performed after written informed consent was obtained from the patient. Histopathology revealed the choroid, iris, ciliary body and trabecular meshwork infiltrated with malignant cells (Figure 4A). Orbit and optic nerve were also involved (Figure 4B). Intra-retinal exudates were noted and the retina was detached with subretinal exudation and some foamy cells. Fibrous membrane was noted between the retina and a diffusely thickened choroid. This was found to be heavily pigmented lymphocytes with small irregular nuclei. Extension of malignant cells to the retrobulbar tissue was also noted (Figure 4C-D). Immunohistochemistry showed positive staining for CD5, CD20, CD23, CD38, CD79a, CD45RO, Bcl-2, Kappa, Lambda, LCA, Vimentin and Ki-67 (5\%-10\% positive cells), whereas CD10, Bcl-6

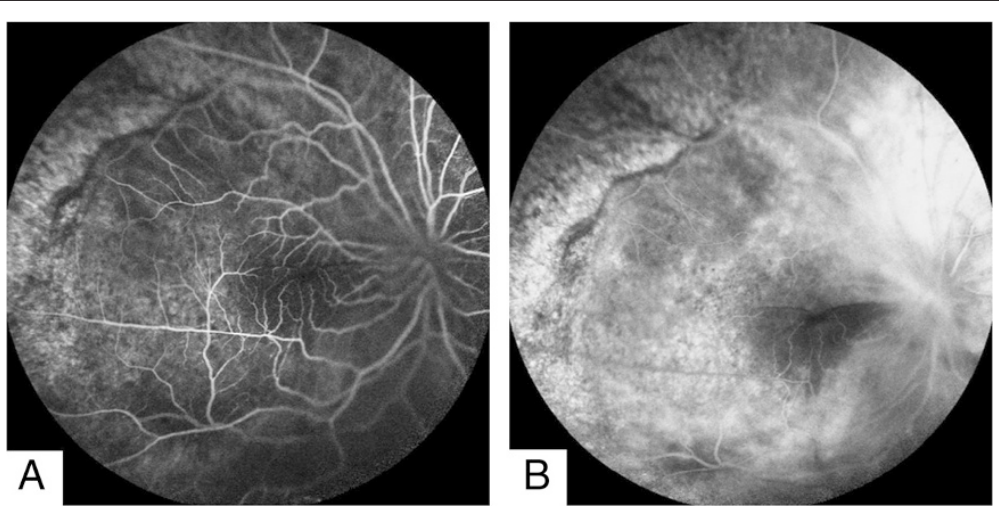

Figure 2 Fluorescence angiography. (A) Early-phase fluorescein angiogram of right eye. (B) Late phase showed macular edema and nonspecific leakage at the level of the RPE. 

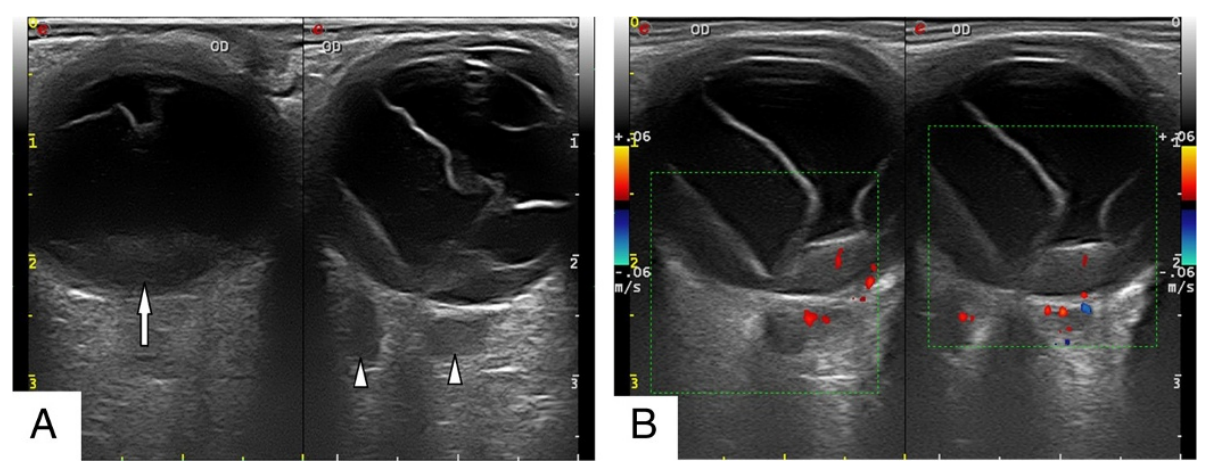

Figure 3 Ultrasonography. (A) B scan showed diffuse thickening of choroid (arrow) with low-reflective retrobulbar masses (arrow heads). (B) Colour Doppler imaging revealed choroidal infiltration and involvement of optic nerve and orbit.

and Cyclin D1 were negative (Figure 5A-H). The diagnosis of primary uveal EMZL was made based on the histomorphology and immunohistochemistry examinations. The patient underwent a systemic work up including positron emission tomography and bone marrow aspiration smears. The results were negative.

\section{Discussion}

Primary uveal lymphoma has been named as "uveal lymphosarcoma", "reactive lymphoid hyperplasia" and "uveal pseudotumours" in the past [8-10]. In 1994, based on the findings of the International Lymphoma Study Group, the term 'extranodal marginal zone B cell lymphoma' was proposed by the Revised European American Lymphoma
(REAL) classification to incorporate both mucosa- and non-mucosa-associated 'MALT' lymphomas [11]. More recently, primary uveal lymphoma was suggested to be accurately subtyped as EMZL of MALT type (WHO lymphoma classification), since its morphological, immunophenotypical, and clinical features were identical to those of EMZL-MALT elsewhere [12].

According to the REAL classification, only 61 EMZL cases (including the present case) have been reported since 1994 (More details can be found in Table 1) [5-7,12-23]. These cases included 24 male and 13 female (patient gender was not reported in 24 cases). The age of the patients at presentation ranged from 33 to 85 years. Majority of the cases involved the choroid. Primary iris lymphomas were unusual,
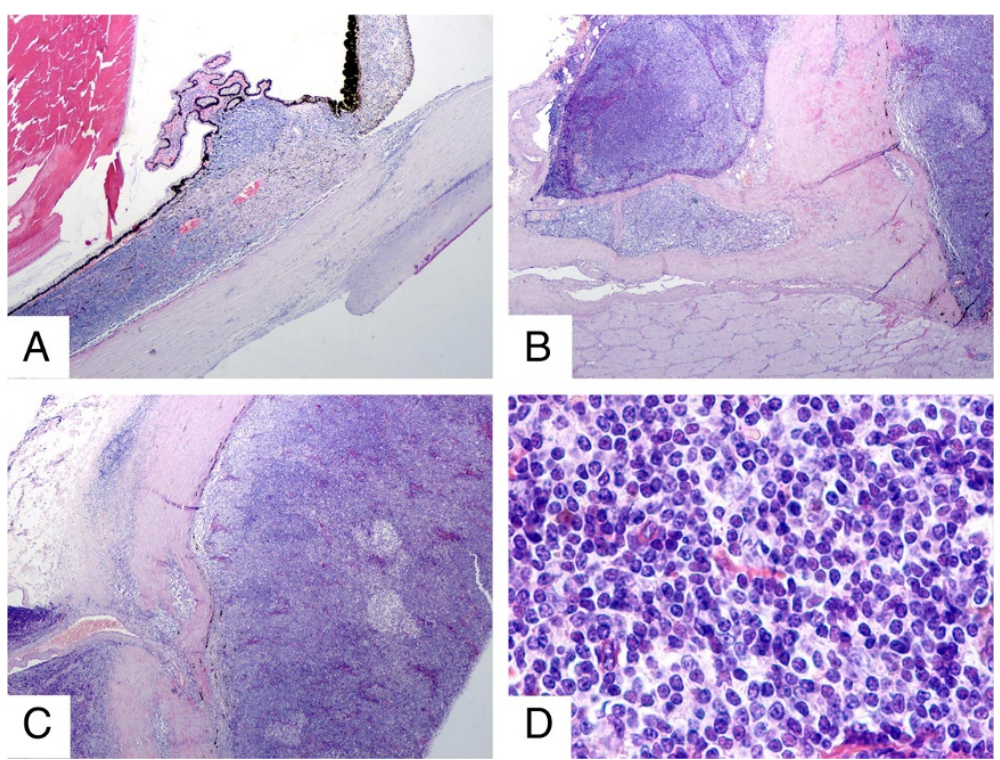

Figure 4 Histologic features of EMZL. (A) Low power magnification showing extensive infiltration of uvea, including choroid, iris, ciliary body and trabecular meshwork (HE; magnification $\times 20$ ). (B) Higher power magnification demonstrating choroidal infiltration by tumor cells, with involvement of optic nerve and orbit ( $\mathrm{HE}$; magnification $\times 40$ ). (C) Increased magnification illustrating the infiltrate of tumor cells with heavily pigmented lymphocytes in choroid and extension of malignant cells to retrobulbar tissue through sclera emissary canal (HE; magnification $\times 40)$. (D) High power magnification revealing an infiltrate of atypical lymphocytes with small irregular nuclei (HE; magnification $\times 400)$. 

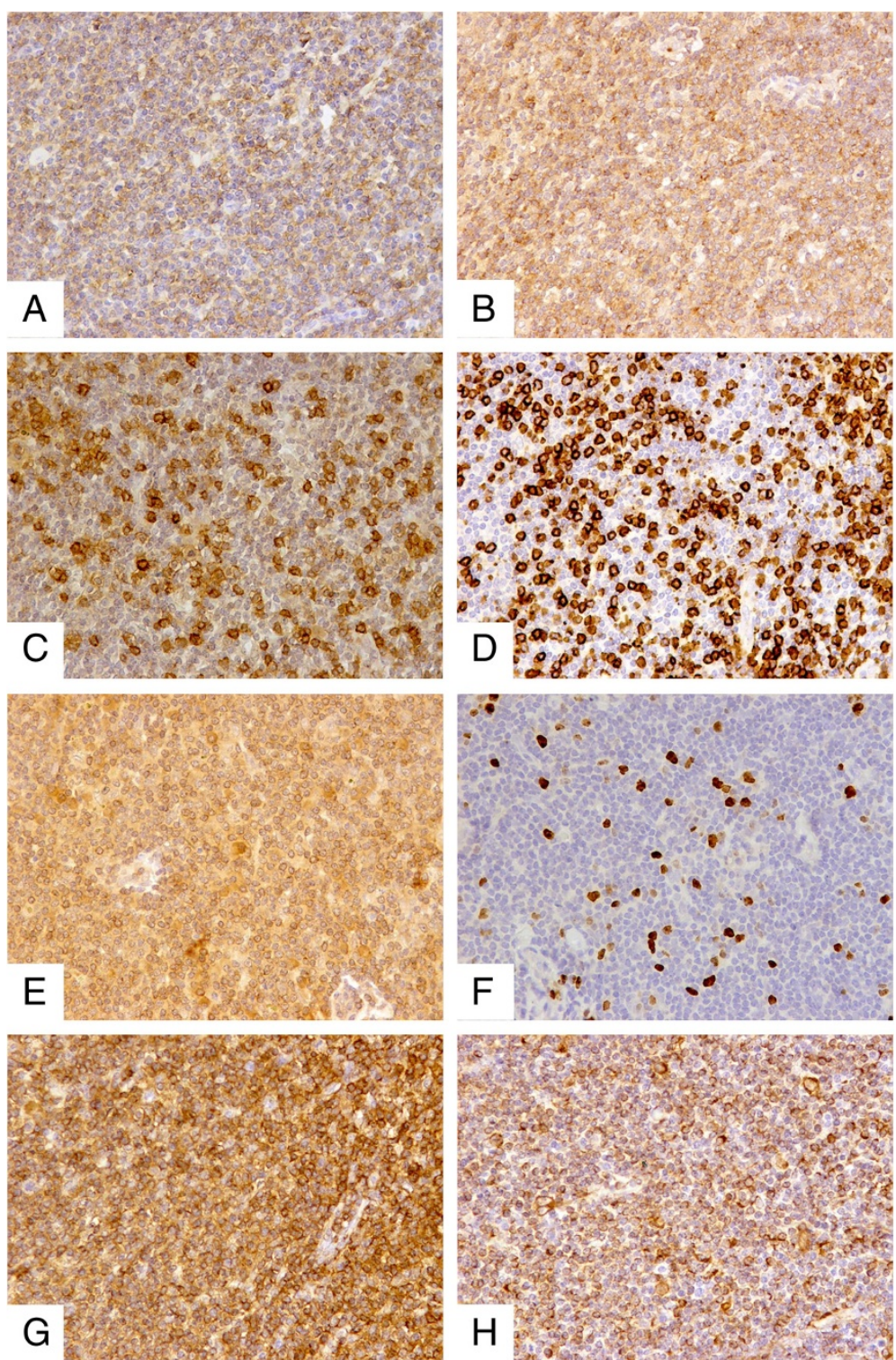

Figure 5 Immunohistochemical expression of EMZL. (A) Tumour cells positive for CD20. (B) Positivity for CD79a. (C) Positivity for CD5. (D) Positivity for CD45RO. (E) Positivity for BCl-2. (F) Positivity for Ki67. (G) Positivity for LCA. (H) Positivity for Vimentin.

with only 2 cases described [5,6]. And only a single case of primary lymphomas limited to the ciliary body has been reported [7]. Most of these cases involved extraocular tissue, with only 10 cases having no extraocular extension [24].

Clinical diagnosis of early EMZL may be difficult. Uveal lymphoma can masquerade as amelanotic uveal melanoma, uveal metastases, uveal effusion syndrome, posterior scleritis, and various uveitities. This presents a significant diagnostic challenge [25-27]. Delays in the diagnosis of uveal lymphoma are common for its insidious and nonspecific onset [16]. Loriaut et al. reported a series of choroidal and adnexal extranodal marginal zone B-cell lymphoma. In their 9 cases, the mean time to diagnosis was 12 months after onset and the longest period for diagnosis delay was 24 months [19]. Typical presenting symptoms such as recurrent episodes of blurred vision, painless visual loss and metamorphopsia, may result from macular serous retinal detachment $[10,12]$. The characteristic findings include clear vitreous, choroidal thickening and no involvement of central nervous system. Imaging techniques, including ultrasonography and orbital MRI, are valuable to detect extraocular involvement [28]. Histopathologic study with immunohistochemical stains remains mandatory to make an accurate diagnosis and classification [12]. Biopsy of the episcleral tumour nodule or an intraocular biopsy is commonly required to determine the nature of the uveal mass 
Table 1 Literature review of EMZL since 1994

\begin{tabular}{|c|c|c|c|c|c|c|c|c|c|}
\hline $\begin{array}{l}\text { No. of } \\
\text { cases }\end{array}$ & Ref/Year & Age/Gender & $\begin{array}{l}\text { Eye/Initial } \\
\text { BCVA }\end{array}$ & $\begin{array}{l}\text { Extraocular } \\
\text { extension }\end{array}$ & Site & Pathology findings & Treatment & $\begin{array}{l}\text { Systemic } \\
\text { work-up }\end{array}$ & $\begin{array}{l}\text { Follow-up } \\
\text { (months) }\end{array}$ \\
\hline 1 & $5 / 2000$ & $51 / F$ & $L / 0.5$ & $\mathrm{~N}$ & Iris & CD20+, CD19+, Kappa LC+ & $\begin{array}{l}\text { Radiotherapy } \\
\text { Enucleation }\end{array}$ & $N$ & 72 \\
\hline 2 & $12 / 2002$ & $63 / \mathrm{M}$ & NA/NLP & $\mathrm{N}$ & Uvea & $\begin{array}{l}\text { CD79a+, CD20+, BSAP+, MUM1+, CD38+, CD138-, Vs38c+, } \\
\text { Kappa LC-, Lambda LC+, IgM-, IgD- }\end{array}$ & Enucleation & N & 156 \\
\hline 3 & & $40 / F$ & NA/NLP & Y & Uvea & $\begin{array}{l}\text { CD79a+, CD20+, BSAP+, MUM1+, CD38+, CD138-, Vs38c-, } \\
\text { Kappa LC-, Lambda LC+, IgM+, lgD-- }\end{array}$ & $\begin{array}{l}\text { Enucleation, } \\
\text { Radiotherapy }\end{array}$ & Y & 300 \\
\hline 4 & & $40 / \mathrm{M}$ & NA/HM & Y & Uvea & 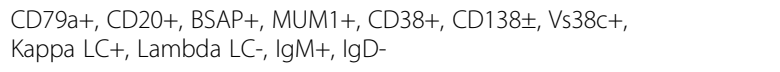 & $\begin{array}{l}\text { Enucleation, } \\
\text { Radiotherapy }\end{array}$ & N & 216 \\
\hline 5 & & $45 / \mathrm{M}$ & $N A / L P$ & Y & Uvea & $\begin{array}{l}\text { CD79a+, CD20+, BSAP+, MUM1+, CD38+, CD138+, Vs38ct, } \\
\text { Kappa LC-, Lambda LC+, IgM+, IgD- }\end{array}$ & $\begin{array}{l}\text { Enucleation, } \\
\text { Radiotherapy }\end{array}$ & N & 120 \\
\hline 6 & & $64 / \mathrm{M}$ & NA/LP & Y & Uvea & $\begin{array}{l}\text { CD79a+, CD20+, BSAP+, MUM1+, CD38-, CD138+, Vs38ct, } \\
\text { Kappa LC-, Lambda LC+, IgM+, lgD- }\end{array}$ & Enucleation & $N$ & 108 \\
\hline 7 & & $33 / \mathrm{M}$ & NA/CF & Y & Uvea & $\begin{array}{l}\text { CD79a+, CD20+, BSAP+, MUM1+, CD38+, CD138-, Vs38c+, } \\
\text { Kappa LC-, Lambda LC+, IgM+, lgD- }\end{array}$ & Enucleation & N & 84 \\
\hline 8 & & $63 / \mathrm{M}$ & NA/0.05 & Y & Uvea & $\begin{array}{l}\text { CD79a+, CD20+, BSAP+, MUM1+, CD38+, CD138-, Vs38ct, } \\
\text { Kappa LC+, Lambda LC-, IgM+, IgD- }\end{array}$ & Enucleation & N & 60 \\
\hline 9 & & $59 / F$ & NA/LP & Y & Uvea & $\begin{array}{l}\text { CD79a+, CD20+, BSAP+, MUM1+, CD38+, CD138-, Vs38c-, } \\
\text { Kappa LC-, Lambda LC-, IgM+, IgD- }\end{array}$ & Enucleation & N & Unknown \\
\hline 10 & & $66 / \mathrm{M}$ & NA/LP & Y & Uvea & $\begin{array}{l}\text { CD79a+, CD20+, BSAP+, MUM1+, CD38+, CD138-, Vs38c-, } \\
\text { Kappa LC-, Lambda LC+, IgM+, lgD-- }\end{array}$ & Enucleation & N & Unknown \\
\hline 11 & & 73/M & $N A / L P$ & Y & Uvea & $\begin{array}{l}\text { CD79a+, CD20+, BSAP+, MUM1+, CD38+, CD138+, Vs38C-, } \\
\text { Kappa LC+, Lambda LC-, IgM+, lgD- }\end{array}$ & Enucleation & Y & 2 \\
\hline 12 & & $81 / \mathrm{M}$ & NA/LP & Y & Uvea & $\begin{array}{l}\text { CD79a+, CD20+, BSAP+, MUM1+, CD38+, CD138+, Vs38c-, } \\
\text { Kappa LC-, Lambda LC+, IgM+, lgD- }\end{array}$ & Enucleation & Y & 180 \\
\hline 13 & & 73/F & NA/NLP & Y & Uvea & $\begin{array}{l}\text { CD79a+, CD20+, BSAP+, MUM1+, CD38+, CD138+, Vs38ct, } \\
\text { Kappa LC+, Lambda LC-, IgM+, IgD- }\end{array}$ & Enucleation & N & Unknown \\
\hline 14 & & $63 / \mathrm{M}$ & NA/N LP & $\mathrm{N}$ & Uvea & $\begin{array}{l}\text { CD79a+, CD20+, BSAP+, MUM1+, CD38+, CD138+, Vs38ct, } \\
\text { Kappa LC+, Lambda LC-, IgM+, IgD- }\end{array}$ & Enucleation & N & 120 \\
\hline 15 & $6 / 2003$ & 83/F & $L / 0.2$ & $\mathrm{~N}$ & Iris & CD20/l-26+, CD79a+, CD3-, CD45RO/UCHL-1- & Radiotherapy & N & 8 \\
\hline 16 & $13 / 2005$ & $45 / \mathrm{M}$ & $L / 0.16$ & N & Choroid & $\begin{array}{l}\text { CD79a+, CD20+, BCL2+, CD43+, CD3-, CD5-, CD23-, CyclinD1-, } \\
\text { Kappa LC+, IgM+, Ki67 10\% }\end{array}$ & Radiotherapy & N & 17 \\
\hline 17 & $7 / 2008$ & $84 / F$ & $R / 0.63$ & N & Ciliary body & CD79a+, CD20+, CD43士, lgM+, CD5-, CD23-, CyclinD1-, Ki-67 5\%-15\% & Radiotherapy & N & 4 \\
\hline 18 & $14 / 2008$ & $57 / F$ & L/0.5 & Conjunctiva & Choroid & CD20+, Bcl2+, CD5-, CD23-, CD43-, Bcl6-, CyclinD1-, Kappa LC+ & Radiotherapy & N & 6 \\
\hline 19 & & $85 / \mathrm{M}$ & NA & N & Choroid & CD20+, CD19+, CD5-, Lambda LC+ & Radiotherapy & N & 3 \\
\hline 20 & $15 / 2009$ & $68 / \mathrm{M}$ & L/HM & Conjunctiva & Choroid & 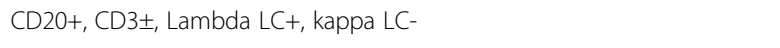 & Radiotherapy & N & 60 \\
\hline 21 & $16 / 2010$ & 80/M & $R / 0.1$ & $\begin{array}{l}\text { Epibulbar } \\
\text { tumor }\end{array}$ & $\begin{array}{l}\text { Iris, ciliary } \\
\text { body, choroid }\end{array}$ & 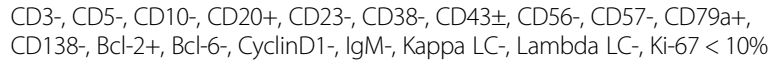 & Enucleation & N & 28 \\
\hline 22 & 17/2011 & 49/M & $\mathrm{R} / \mathrm{CF}$ & $\begin{array}{l}\text { Orbit, sphenoid } \\
\text { bone }\end{array}$ & Choroid & CD20+, CD3-, CD5-, CD10- & $\begin{array}{l}\text { Chemotherapy } \\
\text { Radiotherapy }\end{array}$ & N & NA \\
\hline 23 & $18 / 2012$ & $62 / \mathrm{M}$ & L/0.67 & Orbit, optic & Choroid & CD79+, CD20+, BCL2+, CD10+ (focally), CyclinD1- & Radiotherapy & N & 6 \\
\hline
\end{tabular}


Table 1 Literature review of EMZL since 1994 (Continued)

\begin{tabular}{|c|c|c|c|c|c|c|c|c|c|}
\hline$\overline{24}$ & $19 / 2013$ & $73 / F$ & NA/0.625 & $\begin{array}{l}\text { Conjunctiva, } \\
\text { orbit }\end{array}$ & Choroid & $\begin{array}{l}\text { CD20+++, CD5+, Bcl6+, CyclinD1+, Kappa LC+, Lambda LC -, Ki67 5- } \\
10 \%\end{array}$ & Radiotherapy & $\mathrm{N}$ & 6 \\
\hline 25 & & $46 / \mathrm{M}$ & NA/0.2 & N & Choroid & CD20+++, CD79a+++, CD3+ & Chemotherapy & $\mathrm{N}$ & 84 \\
\hline 26 & & $63 / \mathrm{M}$ & NA/0.16 & Conjunctiva & Choroid & CD20+++, CD5+, CD10-, Bcl6-, CyclinD1-, Ki67 50\% & $\begin{array}{l}\text { Radiotherapy } \\
\text { Chemotherapy }\end{array}$ & $\mathrm{N}$ & 60 \\
\hline 27 & & $54 / \mathrm{F}$ & NA/0.625 & N & Choroid & CD20+++, CD5+, CD23-, BCl6-, CyclinD1-, Kappa LC+, Lambda LC+++ & Radiotherapy & N & 144 \\
\hline 28 & & $64 / F$ & NA/0.005 & Orbit & Choroid & $\begin{array}{l}\text { CD20+++, CD5+, CD10-, CD138+, Bcl6-, CyclinD1-, Kappa LC+, Lambda } \\
\text { LC+++, Ki67 5\% }\end{array}$ & Radiotherapy & $\mathrm{N}$ & 12 \\
\hline 29 & & $54 / F$ & NA/0.5 & Orbit & Choroid & CD20+, CD5+, CD3+, kappa LC-, Lambda LC- & $\begin{array}{l}\text { Radiotherapy } \\
\text { Chemotherapy }\end{array}$ & $\mathrm{N}$ & 120 \\
\hline 30 & & $40 / \mathrm{M}$ & NA/0.8 & N & Choroid & CD20+, BCl2-, Kappa LC+ & $\begin{array}{l}\text { Radiotherapy } \\
\text { Chemotherapy }\end{array}$ & N & 156 \\
\hline 31 & & $53 / F$ & NA/0.1 & Lacrymal gland & Choroid & $\begin{array}{l}\text { CD20++, CD3+, CD5+, CD8+, BCl2+++, Bcl6++, Kappa LC+++, Lambda } \\
\text { LC+, Ki67- }\end{array}$ & Chemotherapy & $\mathrm{N}$ & 53 \\
\hline 32 & & $57 / M$ & NA/0.32 & Conjunctiva & Choroid & CD20+++, CD5+, CD23-, Bcl6+, Kappa LC-, Lambda LC-, Ki67 20\% & Chemotherapy & $\mathrm{N}$ & 33 \\
\hline 33 & $20 / 2013$ & $71 / \mathrm{M}$ & $L / 0.2$ & $\begin{array}{l}\text { Conjunctiva, } \\
\text { optic nerve }\end{array}$ & Choroid & $\mathrm{CD} 20+, \mathrm{CD} 43+, \mathrm{BCl} 2+, \mathrm{CD} 3-$ & Chemotherapy & $\mathrm{N}$ & 12 \\
\hline 34 & $21 / 2013$ & $71 / F$ & L/0.5 & Conjunctiva & Iris, choroid & NA & Radiotherapy & N & 44 \\
\hline 35 & & $71 / \mathrm{M}$ & $\mathrm{R} / 0.05$ & Conjunctiva & Iris, choroid & NA & Radiotherapy & N & 36 \\
\hline 36 & & $75 / M$ & $\mathrm{R} / 0.5$ & $\begin{array}{l}\text { Conjunctiva, } \\
\text { orbit }\end{array}$ & Iris, ciliary body, choroid & NA & Radiotherapy & Unknown & 0 \\
\hline $37-52$ & $22 / 2014$ & NA & NA & NA & Choroid & NA & NA & NA & NA \\
\hline $53-60$ & $23 / 2014$ & NA & NA & NA & NA & NA & NA & NA & NA \\
\hline 61 & $\begin{array}{l}\text { Present } \\
\text { case }\end{array}$ & $38 / \mathrm{M}$ & $\mathrm{R} / 0.1$ & $\begin{array}{l}\text { Orbit, optic } \\
\text { nerve }\end{array}$ & $\begin{array}{l}\text { Iris, ciliary body, choroid, } \\
\text { trabecular meshwork }\end{array}$ & $\begin{array}{l}\text { CD5+, CD10-, CD20+, CD23+, CD38+, CD79a+, BCl-2+, BCl-6-, CyclinD1-, } \\
\text { Kappa LC+, Lambda LC+, Ki-67 5\%-10\% }\end{array}$ & Enucleation & $\mathrm{N}$ & 18 \\
\hline
\end{tabular}

BCVA, best corrected visual acuity; $C F$, counting figure; $F$, female; HM, hand motion; L, left; LP, light perception; $M$, male; N, no; NA, not available; NLP, no light perception; R, right; $Y$, yes. 
[29]. However, it is difficult to obtain a tissue sample. In some inconclusive or late-stage cases, it may be necessary to perform enucleation for the definitive diagnosis $[13,30]$. In the present case, absence of any evidence of systemic disease at presentation and during 2 years of follow-up, could have facilitated the diagnosis of primary EMZL of the uvea.

The exact incidence of primary iris and ciliary body lymphoma remains unknown because only a small number of cases have been reported. This may be due to the evidence that most iris and ciliary body infiltrations have been confirmed only after enucleation or on postmortem histopathology [31]. There were only two reports with diffuse uveal involvement in our literature review. However, no infiltration of trabecular meshwork was mentioned $[16,21]$. In this case we report diffuse uveal involvement (choroid, ciliary body and iris) with focal trabecular meshwork infiltration, which is the first report to the best of our knowledge. However, no secondary glaucoma was found in this case. The mechanism was uncertain and infiltration in early stage may be one of the possible explanations. Our case also masqueraded as posterior scleritis or choroidal hemangioma, presenting diffuse thickened choroid with optic nerve and orbit involvement.

To date, there are no consensus to the optimal treatment for uveal lymphoma due to the small number of such patients and short duration of follow-up. Some authors preferred low-dose external radiotherapy for uveal lymphoma on the basis of satisfactory disease control and few side effects [12]. Although conventional external radiotherapy remains the most frequently used modality, exclusive chemotherapy based on anti-CD20 regimen increasingly becomes one of the treatment choices [19,32].

\section{Conclusions}

In summary, uveal EMZL may present with various features and we report a rare case with diffuse involvement of the uveal and focal trabecular meshwork infiltration. The diagnosis of uveal EMZL is challenging and commonly delayed due to its insidious and nonspecific onset. Early clinical recognition, tissue biopsy, and expert cytologic assessment are critical to achieve early diagnosis and better clinical outcomes. Despite the rarity, uveal EMZL should be included in the differential diagnosis of uveal inflammation or tumors, particularly in patients with persistent signs and symptoms. Non-resolving or recurrent masquerade syndromes not responding to standard treatment should lead to prompt biopsy [33].

\section{Consent}

Written informed consent was obtained from the patient for publication of this Case Report and any accompanying images. A copy of the written consent is available for review by the Editor of this journal.

\section{Abbreviations}

EMZL: Extranodal marginal zone lymphoma; RPE: Retinal pigment epithelium; MALT: Mucosa-associated lymphoid tissue.

\section{Competing interests}

The authors declare that they have no competing interests.

\section{Authors' contributions}

XXG performed the literature review and drafted the manuscript. BL carried out HE and immunohistochemistry stain and interpreted the patient's data. QSY collected clinical information of the patient. XYP supplied the case of the patient and made the final diagnosis of this disease. All authors have read and approved the final manuscript.

\section{Acknowledgements}

We do not have someone to acknowledge to.

\section{Author details}

${ }^{1}$ Beijing Institute of Ophthalmology, Beijing Ophthalmology and Visual Science Key Lab, Beijing Tongren Eye Center, Beijing Tongren Hospital, Capital Medical University, 17 Hougou Lane, Chongnei Street, Beijing 100005, China. ${ }^{2}$ Department of Ophthalmology, Beijing Anzhen Hospital, Capital Medical University, Beijing, China.

Received: 26 November 2014 Accepted: 29 April 2015

Published online: 07 May 2015

\section{References}

1. Freeman C, Freeman LN, Berg JW, Cutler SJ. Occurrence and prognosis of extranodal lymphomas. Cancer. 1972;29:252-60.

2. Coupland SE, Damato B. Lymphomas involving the eye and the ocular adnexa. Curr Opin Ophthalmol. 2006;17:523-31.

3. White WA, Ferry JA, Harris NL, Grove AS. Ocular adnexal lymphoma: a clinicopathologic study with identification of lymphomas of mucosaassociated lymphoid tissue type. Ophthalmology. 1995;102:1994-2006.

4. Whitcup SM, de Smet MD, Rubin BI, Palestine AG, Martin DF, Burnier Jr M, et al. Intraocular lymphoma: clinical and histopathologic diagnosis. Ophthalmology. 1993;100:1399-406.

5. Velez G, de Smet MD, Whitcup SM, Robinson M, Nussenblatt RB, Chan CC. Iris involvement in primary intraocular lymphoma: report of two cases and review of the literature. Surv Ophthalmol. 2000;44:518-26.

6. Yamada K, Hirata A, Kimura A, Tanihara H. A case of primary B-cell type non-Hodgkin lymphoma originating in the iris. Am J Ophthalmol. 2003;136:380-2

7. Coupland SE, Damato B. Understanding intraocular lymphomas. Clin Experiment Ophthalmol. 2008;36:564-78.

8. Triebenstein O. Ein Beitrag zur Frage der aleukamischen Augenveranderungen. Kin Monatsbl Augenheilkd. 1920;64:825-36.

9. Ryan SJ, Zimmerman LE, King FM. Reactive lymphoid hyperplasia. An unusual form of intraocular pseudotumor. Trans Am Acad Ophthalmol Otolaryngol. 1972;76:652-71.

10. Cockerham GC, Hidayat AA, Bijwaard KE, Sheng ZM. Re-evaluation of 'reactive lymphoid hyperplasia of the uvea': an immunohistochemical and molecular analysis of 10 cases. Ophthalmology. 2000;107:151-8.

11. Harris NL, Jaffe ES, Stein H, Banks PM, Chan JK, Cleary ML, et al. A revised European-American classification of lymphoid neoplasms: a proposal from the International Lymphoma Study Group. Blood. 1994;84:1361-92.

12. Coupland SE, Foss HD, Hidayat AA, Cockerham GC, Hummel M, Stein H. Extranodal marginal zone B cell lymphomas of the uvea: an analysis of 13 cases. J Pathol. 2002;197:333-40.

13. Coupland SE, Joussen A, Anastassiou G, Stein H. Diagnosis of a primary uveal extranodal marginal zone B-cell lymphoma by chorioretinal biopsy: case report. Graefes Arch Clin Exp Ophthalmol. 2005;243:482-6.

14. Fuller ML, Sweetenham J, Schoenfield L, Singh AD. Uveal lymphoma: a variant of ocular adnexal lymphoma. Leuk Lymphoma. 2008;49:2393-7.

15. García-Alvarez C, Saornil MA, Blanco G, Méndez MC, López-Lara F. Extranodal B-cell uveal lymphoma with extraocular involvement. Can J Ophthalmol. 2009:44:213-4.

16. Rasic' DM, Stankovic' Z, Terzic' T, Kovacevic' D, Koturovic' Z, Markovic' V. Primary extranodal marginal zone lymphoma of the uvea associated with massive diffuse epibulbar extension and focal infiltration of the optic nerve 
and meninges, clinically presented as uveitis masquerade syndrome: a case report. Med Oncol. 2010;27:1010-6.

17. Tagami M, Nagai T, Sekimukai D, Hara R, Azumi A. Uveal extranodal marginal zone B-cell lymphoma of the mucosa-associated lymphoid tissue type with concomitant extraocular lesions in a Japanese man. Jpn J Ophthalmol. 2011;55:585-7.

18. Baryla J, Allen LH, Kwan K, Ong M, Sheidow T. Choroidal lymphoma with orbital and optic nerve extension: case and review of literature. Can J Ophthalmol. 2012;47:79-81.

19. Loriaut $\mathrm{P}$, Charlotte F, Bodaghi B, Decaudin D, Leblond V, Fardeau C, et al. Choroidal and adnexal extranodal marginal zone B-cell lymphoma: presentation, imaging findings, and therapeutic management in a series of nine cases. Eye (Lond). 2013;27:828-35.

20. Rospond-Kubiak I, Kocięcki J, Stopa M. Primary uveal lymphoma effectively managed with oral chlorambucil: a case report. J Med Case Rep. 2013;7:173.

21. Mashayekhi A, Shields CL, Shields JA. Iris involvement by lymphoma: a review of 13 cases. Clin Experiment Ophthalmol. 2013;41:19-26.

22. Aronow ME, Portell CA, Sweetenham JW, Singh AD. Uveal lymphoma: clinical features, diagnostic studies, treatment selection, and outcomes. Ophthalmology. 2014;121:334-41.

23. Mashayekhi A, Shukla SY, Shields JA, Shields CL. Choroidal lymphoma: clinical features and association with systemic lymphoma. Ophthalmology. 2014;121:342-51

24. Sagoo MS, Mehta H, Swampillai AJ, Cohen VM, Amin SZ, Plowman PN, et al. Primary intraocular lymphoma. Surv Ophthalmol. 2014;59:503-16.

25. Brown SM, Jampol LM, Cantrill HL. Intraocular lymphoma presenting as retinal vasculitis. Surv Ophthalmol. 1994;39:133-40.

26. Gill MK, Jampol LM. Variations in the presentation of primary intraocular lymphoma: case reports and a review. Surv Ophthalmol. 2001;45:463-71.

27. Rothova A, Ooijman F, Kerkhoff F, Van Der Lelij A, Lokhorst HM. Uveitis masquerade syndromes. Ophthalmology. 2001;108:386-99.

28. Read RW, Zamir E, Rao NA. Neoplastic masquerade syndromes. Surv Ophthalmol. 2002;47:81-124.

29. Coutinho AB, Muccioli C, Martins MC, Belfort Jr R, Sant' Anna AE, Burnier Jr MN. Extranodal B-cell lymphoma of the uvea: a case report. Can J Ophthalmol. 2005;40:623-6

30. Gündüz K, Shields JA, Shields CL, Eagle Jr RC, Diniz W, Mercado G, et al. Transscleral choroidal biopsy in the diagnosis of choroidal lymphoma. Surv Ophthalmol. 1999:43:551-5.

31. Qualman SJ, Mendelsohn G, Mann RB, Green WR. Intraocular lymphomas: natural history based on a clinicopathologic study of eight cases and review of the literature. Cancer. 1983:52:878-86.

32. Paik JS, Cho WK, Lee SE, Choi BO, Jung SE, Park GS, et al. Ophthalmologic outcomes after chemotherapy and/or radiotherapy in non-conjunctival ocular adnexal MALT lymphoma. Ann Hematol. 2012;91:1393-401.

33. Teoh SC, Dick AD. Diagnostic techniques for inflammatory eye disease: past, present and future: a review. BMC Ophthalmol. 2013;13:41.

\section{Submit your next manuscript to BioMed Central and take full advantage of:}

- Convenient online submission

- Thorough peer review

- No space constraints or color figure charges

- Immediate publication on acceptance

- Inclusion in PubMed, CAS, Scopus and Google Scholar

- Research which is freely available for redistribution

Submit your manuscript at www.biomedcentral.com/submit 